\title{
Synergetic effects of doxycycline-loaded chitosan nanoparticles for improving drug delivery and efficacy
}

This article was published in the following Dove Press journal:

International Journal of Nanomedicine

22 June 2012

Number of times this article has been viewed

\section{Natasha F Cover' \\ Susana Lai-Yuen ${ }^{2}$ \\ Anna K Parsons ${ }^{3}$ \\ Arun Kumar ${ }^{4}$}

'Department of Chemical and Biomedical Engineering, University of South Florida, Tampa, Florida, ${ }^{2}$ Department of Industrial and Management Systems Engineering, University of South Florida, Tampa, Florida, ${ }^{3}$ Department of Obstetrics and Gynecology, University of South Florida, Tampa, Florida, ${ }^{4}$ Department of Medical Technology, University of Delaware, Newark, Delaware, USA
Correspondence: Arun Kumar University of Delaware, College of Health Science, Department of Medical Technology, Nanomedicine Research Lab, 305 C Willard Hall, Newark DE 19716,

Delaware, USA

Tel +l $30283 \mid 4552$

$\mathrm{Fax}+|30283| 4 \mid 82$

Email arunk@udel.edu
Introduction: Doxycycline, a broad-spectrum antibiotic, is the most commonly prescribed antibiotic worldwide for treating infectious diseases. It may be delivered orally or intravenously but can lead to gastrointestinal irritation and local inflammation. For treatment of uterine infections, transcervical administration of doxycycline encapsulated in nanoparticles made of biodegradable chitosan may improve sustained delivery of the drug, thereby minimizing adverse effects and improving drug efficacy.

Methods and materials: As a first step toward assessing this potential, we used an ionic gelation method to synthesize blank and doxycycline-loaded chitosan nanoparticles (DCNPs), which we then characterized in terms of several properties relevant to clinical efficacy: particle size, shape, encapsulation efficiency, antibacterial activity, and in vitro cytotoxicity. Two particle formulations were examined, with one (named DCNP6) containing approximately 1.5 times the crosslinker concentration of the other (DCNP4).

Results: The two formulations produced spherically shaped drug-loaded nanoparticles. The spheres ranged in size from 30 to $220 \mathrm{~nm}$ diameter for DCNP4 and 200 to $320 \mathrm{~nm}$ diameter for DCNP6. Average encapsulation yield was 53\% for DCNP4 and 56\% for DCNP6. In terms of drug release, both formulations showed a burst effect within the first 4 to 5 hours, followed by a slow, sustained release for the remainder of the 24-hour monitoring period. The in vitro antibacterial activity against Escherichia coli was high, with both formulations achieving more than $90 \%$ inhibition of 4-hour bacterial growth. Cytotoxic effects of the DCNPs on normal human ovarian surface epithelial cells were significantly lower than those of unencapsulated doxycycline. After 5 days, cultures exposed to the unencapsulated antibiotic showed a $61 \%$ decrease in cell viability, while cultures exposed to the DCNPs exhibited less than a $10 \%$ decrease.

Conclusion: These laboratory results suggest that DCNPs show preliminary promise for possible eventual use in transcervical drug delivery and improved efficacy in the treatment of bacterial uterine infections.

Keywords: chitosan, doxycycline, ionic gelation, nanoparticles, cytotoxicity

\section{Introduction}

According to the Centers for Disease Control and Prevention (CDC), more than 1 million women in the USA experience acute pelvic inflammatory disease (PID), with US\$1-2 billion spent annually for treatment of the disease and its sequelae. ${ }^{1-6}$ The CDC recommends $200 \mathrm{mg}$ of doxycycline, an inexpensive broad-spectrum drug, to be administered for treatment orally or intravenously every 12 hours. $^{7}$ Doxycycline is used to treat both intracellular and extracellular bacterial infections such as aerobic and anaerobic Gram-positive and Gram-negative bacteria, and other microorganisms such as chlamydia, protozoa, mycoplasma, mycobacteria, and spirochetes. ${ }^{8,9}$ Due 
to doxycycline's antibacterial effects on a wide range of pathogens, it is currently one of the most commonly prescribed antibiotics worldwide for treating infectious diseases. ${ }^{9,10}$ However, when doxycycline is administered orally or intravenously, it may cause esophageal ulcers, gastrointestinal irritation, and local inflammation, which may in turn lead to premature cessation of treatment. ${ }^{11-13}$ Furthermore, the use of doxycycline may also result in mechanical scarring of tissues and cavities in the body as well as blood vessels. ${ }^{14-20}$

In recent years, drug encapsulation and delivery via small particles has garnered increasing interest. Encapsulation may help prevent adverse effects by protecting sensitive tissues from fast drug exposure while also improving drug efficacy by achieving slow, sustained release directly at the infection site. Having patients complete the entire treatment cycle would also increase the likelihood of complete pathogen elimination. These properties suggest that the encapsulation of doxycycline into biodegradable nanoparticles could perhaps be used to eventually improve treatment of PID via direct transcervical drug delivery.

Chitosan is a promising candidate for encapsulating and delivering doxycycline or other drugs directly to an infection site. This naturally occurring cationic polysaccharide possesses muco-adhesive properties that enable its transport across the mucosal membrane. ${ }^{21-26}$ In addition, it slowly degrades to nontoxic amino sugars that can be completely absorbed by the body. These properties - biocompatibility and biodegradability - are highly desirable for encapsulation materials. ${ }^{26-28}$ Particle size and co-occurring substances are other important considerations. Encapsulation of doxycycline into chitosan microspheres has been previously accomplished using a water-in-oil emulsion technique, but this approach can introduce oil and other harsh chemicals to the body. ${ }^{29}$ Chitosan particles prepared by an alternative method may offer a more benign delivery vehicle. Chitosan can also be used to form nanoparticles, which have a higher cellular uptake than microparticles, thus allowing for greater intracellular delivery of the encapsulated (drug) molecule. ${ }^{30-32}$

Encapsulation methods are chosen in part based on polymer properties, drug hydrophobicity, and desired final particle size. The molecular weight of the chitosan plays a vital role in particle size and formation, as a higher molecular weight produces larger particles. ${ }^{33,34}$ An ideal method should also ensure drug encapsulation while minimizing drug loss and maintaining pharmacological activity. Commonly used methods for preparing chitosan-based drug delivery systems include emulsion crosslinking, ${ }^{35,36}$ emulsion-droplet coalescence, ${ }^{28,35}$ spray drying, ${ }^{37}$ sieving, ${ }^{35}$ coacervation/precipitation, ${ }^{29,35,36}$ and ionic gelation. ${ }^{31,34,36,38,39}$ Methods such as emulsion crosslinking and emulsion-droplet coalescence involve the use of a harsh crosslinking agent that might induce an unnecessary chemical reaction with the active agents. Spray drying and sieving produce relatively large microparticles, with diameters of approximately 1-10 $\mu \mathrm{m}$ and 543-698 $\mu \mathrm{m}$, respectively. ${ }^{35}$ Ionic gelation methods, in contrast, offers the advantage of simplicity with no requirement for complicated equipment as well as electrostatic crosslinking instead of chemical crosslinking, thereby reducing the likelihood of inducing toxic effects with the particles.

In this study, we investigated chitosan nanoparticles as a potential carrier of doxycycline to improve drug delivery and treatment efficacy. The goal was to undertake an initial assessment of particle properties relevant to encapsulated drug delivery through a localized (ie, transcervical) route using a patent-pending device design fabricated by our group. The chosen method for our preparation was ionic gelation. We created and then characterized doxycycline-loaded chitosan nanoparticles (DCNPs) in terms of their morphology (size and shape), drug encapsulation efficiency and release rates, in vitro antibacterial activity, and in vitro cytotoxicity.

\section{Materials and methods Materials}

Doxycycline, phosphate-buffered saline, Millipore watersoluble tetrazolium salts (WST)-1 Cell Proliferation Assay, and acetic acid were obtained from Fisher Scientific (Hampton, NH). Sodium tripolyphosphate (TPP), fetal bovine serum, medium 199, and MCDB 105 medium were supplied by Sigma Chemical Company (St Louis, MO). Partially (75\%) deacetylated chitosan $(60 \mathrm{kDa})$ derived from shrimp shells was obtained in powder form from Sigma-Aldrich (St Louis, MO). All other chemicals were of analytical grade and were obtained from a variety of vendors. Eschericha coli (ATCC 25922) was purchased from American Type Culture Collection (Manassas, VA).

\section{Preparation of nanoparticles}

The chitosan nanoparticles were prepared using the ionic gelation method described by Clavo et al. ${ }^{38}$ Chitosan powder was dissolved, $0.2 \%$ weight by volume (w/v), in $0.25 \mathrm{M}$ acetic acid; this solution was magnetically stirred overnight at a speed of $400 \mathrm{rpm}$ at room temperature. The acetic acid protonates the amine group of the chitosan molecule for a more stable interaction with the crosslinking agent and the drug. ${ }^{33,40}$ The crosslinker, TPP, was prepared by dissolving the powder in $0.25 \mathrm{M}$ acetic acid at two different concentrations: $0.42 \% \mathrm{w} / \mathrm{v}$ (referred to here as formulation $8[\mathrm{~F} 8]$ ) and $0.60 \% \mathrm{w} / \mathrm{v}$ (formulation 10 [F10]). In a separate 
set of experiments, we examined 64 different combinations of solutions and procedural steps and identified these two formulations as consistently producing particles within a predictable formulation-specific size range.

Blank nanoparticles were formed by combining the chitosan and TPP solutions for a total volume of $2 \mathrm{~mL}$; the chitosan-to-TPP ratio was 23:1 for F8 and 16:1 for F10. To initiate ionic gelation (nanoparticle formation), TPP was added dropwise to the stirred chitosan solution and the combined solution was then stirred for an additional hour. Blank nanoparticles prepared using F8 $(0.42 \% \mathrm{w} / \mathrm{v}$ TPP) are here referred to as BKCNP4, while blanks prepared using F10 $(0.60 \% \mathrm{w} / \mathrm{v}$ TPP) are referred to as BKCNP6. The solution with precipitated nanoparticles was centrifuged at $10,000 \mathrm{rpm}$ for 5 minutes and the resulting supernatant was saved for later analysis of its doxycycline content. The particles in the microcentrifuge tube were washed/resuspended by adding $2 \mathrm{~mL}$ nanopure water and the tube was again centrifuged at $10,000 \mathrm{rpm}$ for 5 minutes. The second supernatant was removed and discarded as preliminary tests had shown that the second supernatant contained no doxycycline residue. Finally, the particles were resuspended in $2 \mathrm{~mL}$ nanopure water before further analysis.

A doxycycline stock solution was prepared by dissolving doxycycline powder in nanopure water to achieve a final concentration of $200 \mathrm{mg}$ doxycycline per $\mathrm{mL}$ solution.

$$
\text { EE }(\%)=\frac{\begin{array}{l}
\text { Drug } @ \text { synthesis }(\mathrm{mg} / \mathrm{mL})- \\
\text { Free drug in supernatant }(\mathrm{mg} / \mathrm{mL})
\end{array} \text { synthesis }(\mathrm{mg} / \mathrm{mL})}{100}
$$

Drug-loaded chitosan nanoparticles were then prepared according to the procedure outlined above, except that $100 \mu \mathrm{L}$ of the doxycycline stock solution was added dropwise to the stirred chitosan solution just before the TPP addition. In every batch of DCNP solution, the final doxycycline concentration was $20 \mathrm{mg} / \mathrm{mL}$. Drug-loaded chitosan nanoparticles prepared using $0.42 \% \mathrm{w} / \mathrm{v}$ TPP are here referred to as DCNP4; those prepared with $0.60 \% \mathrm{w} / \mathrm{v}$ TPP are referred to as DCNP6. All analyses of blank particles, drug-loaded particles, and supernatant were initiated within 24 hours of particle preparation.

\section{Nanoparticle characterization}

Particle size distributions for blank nanoparticles and DCNPs were determined with a Nanotrac Particle Size Analyzer (Microtrac, Largo, FL), which measures dynamic light scattering by particles in solution. The analyses were performed on samples of nanoparticles suspended in $1 \mathrm{~mL}$ of nanopure water. The shapes of the blank particles and DCNPs were examined using a JEM-1400 (Jeol, Tokyo, Japan) transmission electron microscope (TEM). Particles to be used for TEM examination were first dried under vacuum and stored in the dark at $4^{\circ} \mathrm{C}$. TEM samples were then prepared by depositing a drop of nanoparticles onto a formvar-coated copper grid, which was allowed to dry by vacuum before TEM analysis.

\section{Encapsulation efficiency}

Incorporation of doxycycline into the particles was characterized by measuring the doxycycline contained in the centrifugation supernatant. Since the total amount of drug in each formulation batch was known ( $2 \mathrm{~mL}$ solution with a doxycycline concentration of $20 \mathrm{mg} / \mathrm{mL}$ ), any doxycycline not found in the supernatant could be assigned to the particles. Doxycycline in the supernatant was quantified using a NanoDrop spectrophotometer (ND-1000; NanoDrop, Wilmington, DE). According to the Beer-Lambert equation, the doxycycline concentration, c, is given by $\mathrm{c}=\mathrm{A} / \varepsilon \mathrm{L}$, where $\mathrm{A}$ is light absorbance at $220 \mathrm{~nm}$ wavelength, $\varepsilon$ is the molar absorptivity coefficient (121.39 $\left.\mathrm{M}^{-1} \mathrm{~cm}^{-1}\right)$, and $\mathrm{L}$ is the path length $(0.01 \mathrm{~cm})$. All measurements were performed in triplicate $(n=3)$. The encapsulation efficiency (EE, \%) was calculated using equation 1.

\section{Assessment of drug release}

To determine the rate at which doxycycline was released by the nanoparticles, the particles were resuspended in a drug-free solution that was analyzed for doxycycline content at a predetermined time interval. To begin, dried fresh nanoparticles of known antibiotic content were first resuspended in $2 \mathrm{~mL}$ of nanopure water. A small aliquot of this particle-laden solution was then added to phosphate-buffered saline-ethanol solution to produce a final volume of $2 \mathrm{~mL}$ with an initial concentration of $100 \mu \mathrm{g}$ doxycycline per $\mathrm{mL}$. This solution was incubated at $37^{\circ} \mathrm{C}$ under gentle agitation. At each specified time point $(0.5,1,2,3,4,5,6,7,8,16$, and 24 hours) thereafter, the sample was centrifuged and the supernatant was isolated and analyzed by Nano-drop spectrophotometry to determine the amount of doxycycline in solution. All measurements were performed in triplicate $(\mathrm{n}=3)$ for each formulation. The percentage of drug released at each time point was calculated according to equation 2 .

Drug release $(\%)=\frac{\text { Drug in solution }(\mu \mathrm{g} / \mathrm{mL})}{\text { Initial drug in particles }(\mu \mathrm{g} / \mathrm{mL})} \times 100$

\section{Assessment of antibacterial activity}

To determine the antibacterial activity of the DCNPs, minimum inhibitory concentrations (MICs) and minimum bactericidal 
concentrations (MBCs) were evaluated. The procedures for both assays were adopted from Lee et al. ${ }^{41} \mathrm{MIC}$ is the lowest concentration of DCNPs that inhibits bacterial growth. For our analyses, a visual turbidimetric method was used. Freshly prepared nanoparticles, blank and drug-loaded, were ultraviolet-sterilized for 10 minutes. The particles were then resuspended in a volume of sterile water sufficient to achieve a final doxycycline concentration of $100 \mu \mathrm{g} / \mathrm{mL}$. A $500 \mu \mathrm{L}$ aliquot of this solution with sterilized particles was added to a tube containing Luria-Bertani broth for a total volume of $2 \mathrm{~mL}$. A serial dilution, with a dilution factor of 0.3 , was performed for the remaining six tubes. A parallel series of experiments was also run using unencapsulated doxycycline.

Under sterile conditions, the tubes containing particles were inoculated with $1.0 \times 10^{5}$ colony-forming units $/ \mathrm{mL}$ of E. coli cells in Luria-Bertani broth then incubated at $37^{\circ} \mathrm{C}$ under agitation for 4 hours. Following the incubation, the tubes were assessed visually for the appearance of turbidity (ie, bacterial growth). Among the tubes that showed no visual turbidity - that is, complete inhibition of visible $E$. coli growth - the one with the lowest doxycycline concentration was identified as the MIC tube for that series. All MIC tubes were analyzed to assess the amount of bacteria present by measuring optical density of the suspension at $600 \mathrm{~nm}\left(\mathrm{OD}_{600}\right)$ and then calculating the number of bacterial cells present.

The MBC is the minimum concentration of DCNPs that will kill $99 \%$ of the bacterial cells initially present. To determine this value, $100 \mu \mathrm{L}$ aliquots of liquid culture (broth + nanoparticles + bacteria) from each series' MIC tube and the two tubes prior (ie, containing slightly more doxycycline) were plated and incubated at $37^{\circ} \mathrm{C}$ overnight. As a positive control, an additional plate was plated with broth plus E. coli (no particles or drug); as a negative control, another plate was plated with broth plus blank particles plus $E$. coli (no drug). All samples were plated in triplicate. Plates were observed for colony growth, and the plate with the fewest colony colonies was identified as the MBC plate.

\section{Assessment of cytotoxicity}

Cytotoxicity of the DCNPs was determined by treating normal human ovarian surface epithelial (OSE) cells with different concentrations of doxycycline-loaded nanoparticles, then monitoring cell viability over the next 5 days. The OSE cells were cultured for 4 to 7 days in flasks containing medium 199/MCDB105 media supplemented with 10\% fetal bovine serum. The cells were removed from the flasks and counted, and then $100 \mu \mathrm{L}$ of medium containing cells was added to the wells of a 96-well plate to give final cell concentrations of $5 \times 10^{2}, 1.0 \times 10^{3}$, or $2.0 \times 10^{3}$ cells $/ \mathrm{mL}$. After 24 hours incubation at $37^{\circ} \mathrm{C}$, the cells were treated with blank nanoparticles, DCNP4 ( 1 and $2 \mu \mathrm{g} / \mathrm{mL}$ ), DCNP6 ( 1 and $2 \mu \mathrm{g} / \mathrm{mL}$ ), or unencapsulated doxycycline ( 1 and $2 \mu \mathrm{g} / \mathrm{mL})$. The plate was then incubated at $37^{\circ} \mathrm{C}$. Bright microscopy was used to examine the cell morphology after treatment just before the assessing for cytotoxicity. Cytotoxicity was assessed on days $1,3$, and 5 by WST-1 assay. WST-1 assay reagent (10 $\mu \mathrm{L})$ was added to each well, followed by incubation for another 4 hours at $37^{\circ} \mathrm{C}$ and then spectrophotometric assessment of cell viability. Mitochondrial dehydrogenases produced by viable cells reduce the WST-1 reagent to form formazan dye in an amount directly proportional to the number of metabolically active cells in the well. This dye was quantified using a BioTek Synergy (Winooski, VT) multiplate reader to measure absorbance at $450 \mathrm{~nm}$ (reference wavelength was $630 \mathrm{~nm})$. All treatments were assayed in triplicate $(\mathrm{n}=3)$.

\section{Statistical analysis}

A two-way analysis of variance was employed to identify statistical differences among the various experimental groups and their corresponding control groups. Experimental groups with $P$-values of $P<0.05$ were considered to be statistically significant.

\section{Results and discussion Physical characterization of drug-loaded nanoparticles}

Blank and DCNPs were successfully prepared using an ionic gelation method. The blank particles, BKCNP4 and BKCNP6, were relatively large, with an average diameter of 4900 and $4450 \mathrm{~nm}$, respectively (data not shown). Both groups of particles were spherical in shape with a narrow particle size distribution. The drug-loaded particles were smaller than their blank counterparts. The DCNP4 particles (Figure 1A), with an average particle diameter of $44.50 \mathrm{~nm}$, were two orders of magnitude smaller than their corresponding blanks and had a wider particle size distribution profile. DCNP4s were spherical in shape with smooth edges (Figure 1B). Similarly, the DCNP6 particles (Figure 1C), with an average diameter of $280 \mathrm{~nm}$, were small compared to their blank counterparts about $1 / 15$ the size - but were significantly larger than the DCNP4s. In contrast to the DCNP4s, the DCNP6 particles exhibited a very narrow particle size distribution profile. The DCNP6 particles were spherical like the DCNP4s but had edges that were not as smooth (Figure 1D).

Since the conditions that varied between the two formulations for preparing these particles was the 


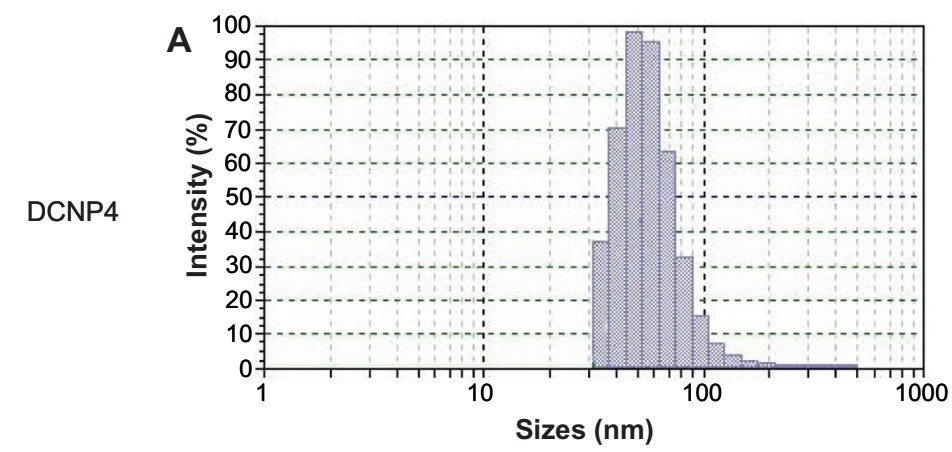

B
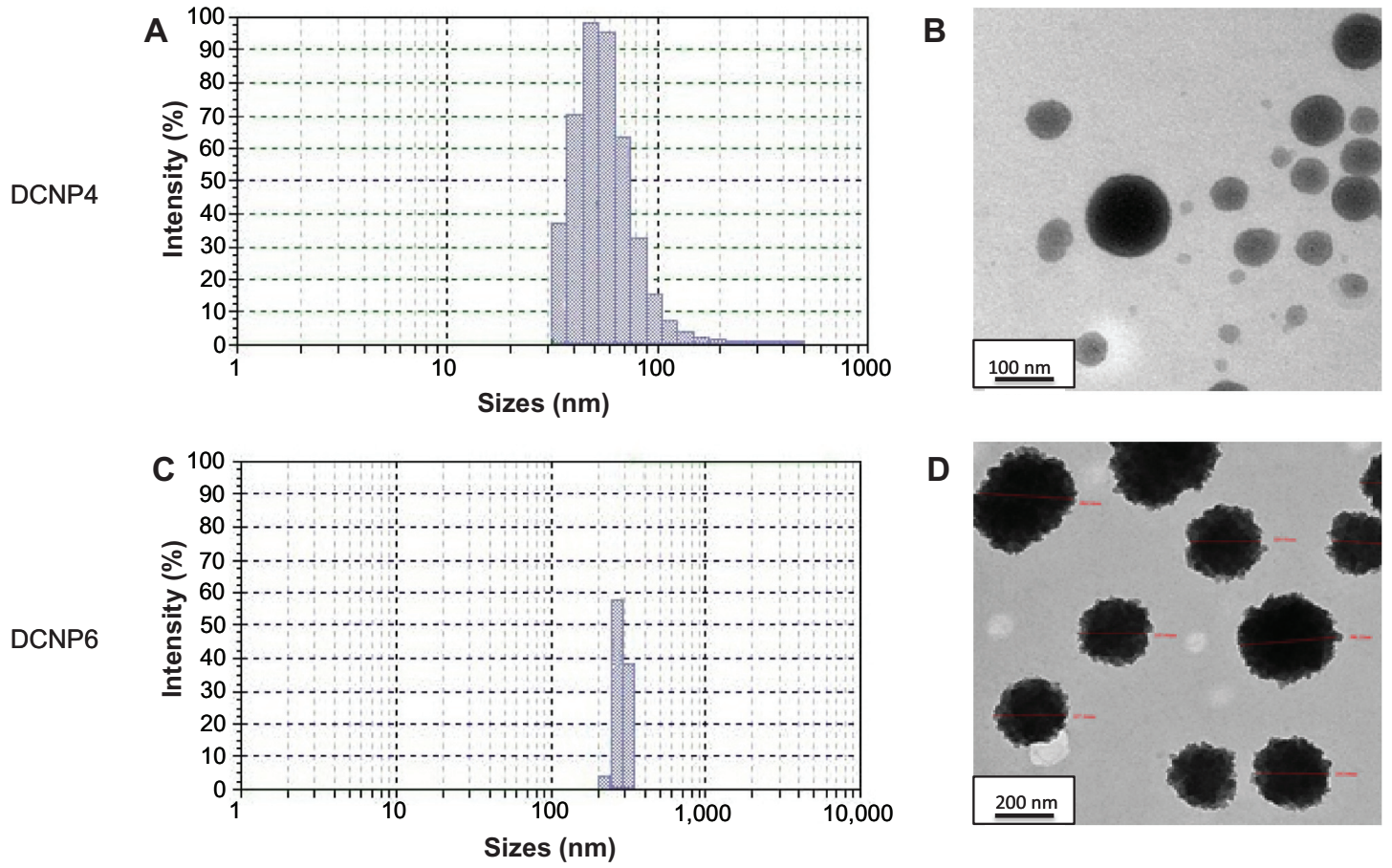

Figure I Particle size distribution (A and C) for DCNP4 and DPNC6, and transmission electron microscopy images (B and D), for DCNP4 and DPNC6 respectively.

concentration of the TPP crosslinker and the resulting ratio of chitosan to TPP, it can be speculated that the concentration of the crosslinker plays a role in determining particle size. Also, inclusion of the doxycycline in the formulations produced particles significantly smaller than the blanks, which is an interesting finding that our group is currently investigating. Having a narrower particle size distribution profile - ie, particles of more nearly uniform size - is also important. The more similar the particles are in size, the more equally the drug will be distributed among the particles, which will normalize the rate of drug release.

\section{Encapsulation efficiency}

Across all batches of DCNP4, the lowest encapsulation efficiency was $22 \%$, the highest was $69 \%$, and the average was $53 \% \pm 19 \%$. For DCNP6, the lowest encapsulation efficiency was $41 \%$, the highest was $68 \%$, and the average was $56 \% \pm 10 \%$. Even though DCNP6 was substantially larger in diameter, there was no significant difference in the amount of drug encapsulated for each type of DCNP.

\section{Drug release}

Doxycycline was released from the DCNPs in a burst-effect manner followed by a slow, sustained release (Figure 2). For DCNP4, the burst effect occurred within the first 5 hours; for DCNP6, within the first 4 hours. Within the first couple of hours after this initial burst, the amount of drug released decreased then was followed by a sustained release for the remaining time. By the end of the 24-hour monitoring period, DCNP6 had released more total drug than had DCNP4. The difference between the amounts of drug released by the two different particle formulations can be attributed to the differences in particle size, with the larger particles (DCNP6) releasing more antibiotic than the smaller ones (DCNP4). A burst effect followed by slow sustained release, as demonstrated by both nanoparticle formulations, is ideal for treating microbial infections

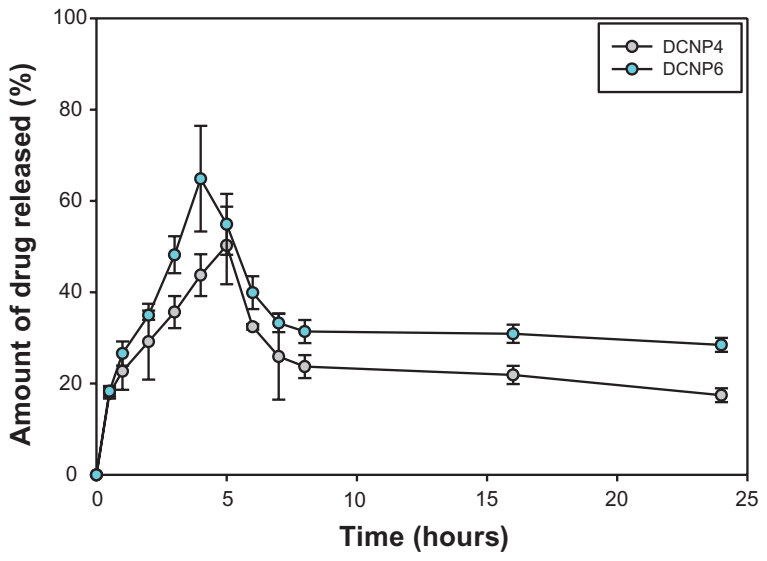

Figure 2 The amount of doxycycline release over a 24-hour period for DCNP4 and DCNP6 both with an initial burst effect within the first 4 to 5 hours followed by a decrease in amount of drug being release then to a slow sustained amount for the remaining hours.

Note: Data shown are the mean \pm standard deviation $(n=3)$. 
such as PID, where delivering the particles in a local (ie, transcervical) manner to the reproductive lumen would provide an increasing amount of doxycycline initially, followed by a reduced amount later, thus increasing the likelihood of total pathogen elimination.

\section{Antibacterial activity}

After 4 hours incubation at $37^{\circ} \mathrm{C}$, the drug-loaded nanoparticles' minimum inhibitory doxycycline concentration, MIC, was $16 \mu \mathrm{g} / \mathrm{mL}$ for DCNP4 and $13 \mu \mathrm{g} / \mathrm{mL}$ for DCNP6. Figure 3 shows the MIC cases for DCNP4 $(16 \mu \mathrm{g} / \mathrm{mL})$ and DCNP6 (13 $\mu \mathrm{g} / \mathrm{mL}$ ) with unencapsulated doxycycline (Doxy $13 \mu \mathrm{g} / \mathrm{mL}$ ) and blank particles serving as controls. For both types of DCNPs, more than $92 \%$ E. coli growth inhibition was observed. The minimum bactericidal concentration, $\mathrm{MBC}$, was $48 \mu \mathrm{g} / \mathrm{mL}$ and $40 \mu \mathrm{g} / \mathrm{mL}$ for DCNP4 and DCNP6, respectively. Unencapsulated doxycycline treatments (Doxy), conducted at the same concentrations as the DCNP drug concentrations, resulted in the nearelimination of $E$. coli. These data suggest that the unencapsulated doxycycline had a higher antibacterial activity than the DCNPs within the 4-hour period. However, because the DCNPs release the doxycycline in a slow and sustained manner, we speculate that the nanoparticles' antibacterial activity would have been higher if the incubation period had been extended beyond 4 hours.

\section{Cytotoxicity}

For the case of initial human OSE cell densities of $5 \times 10^{2}$, no cytotoxicity (relative to the cells-only case) was induced by the $1 \mu \mathrm{g} / \mathrm{mL}$ or $2 \mu \mathrm{g} / \mathrm{mL}$ dosages of either DCNP formulation - in other words, cells treated with the DCNPs for 5 days showed high cell viability (Figure 4). In fact, a significant increase in cell proliferation relative to the cells-only case was often observed when the OSE cells were treated with blank or doxycycline-loaded nanoparticles. In contrast, unencapsulated doxycycline at the same dosages induced severe cell toxicity: only $39 \%$ of the original population remained viable after the 5-day treatment. Cells treated with both dosages of DCNP4 or with BKCNP4 had a higher viability than did untreated cells. For DCNP6, the viability of cells treated with $1 \mu \mathrm{g} / \mathrm{mL}$ was higher than for untreated cells, but cells treated with $2 \mu \mathrm{g} / \mathrm{mL}$ showed lower viability. Nevertheless, the DCNP6 case still showed greater cell viability than did the unencapsulated drug treatments. Data from the wells with $1.0 \times 10^{3}$ and $2.0 \times 10^{3}$ initial cell densities are not presented because of cell overcrowding over the 5-day period.

These cytotoxicity results show that encapsulation of doxycycline into the chitosan polymer reduces the toxicity that is normally induced by the unencapsulated drug. The differences between the DCNP4 and DCNP6 cytotoxicity results are possibly due to the differences in their size and the amount of drug released, where the DCNP6s were observed to release more doxycycline than did the DCNP4s. Further exploration and evaluation of the effects of chitosan particles on cell growth is necessary to explain the observed increase in proliferation.

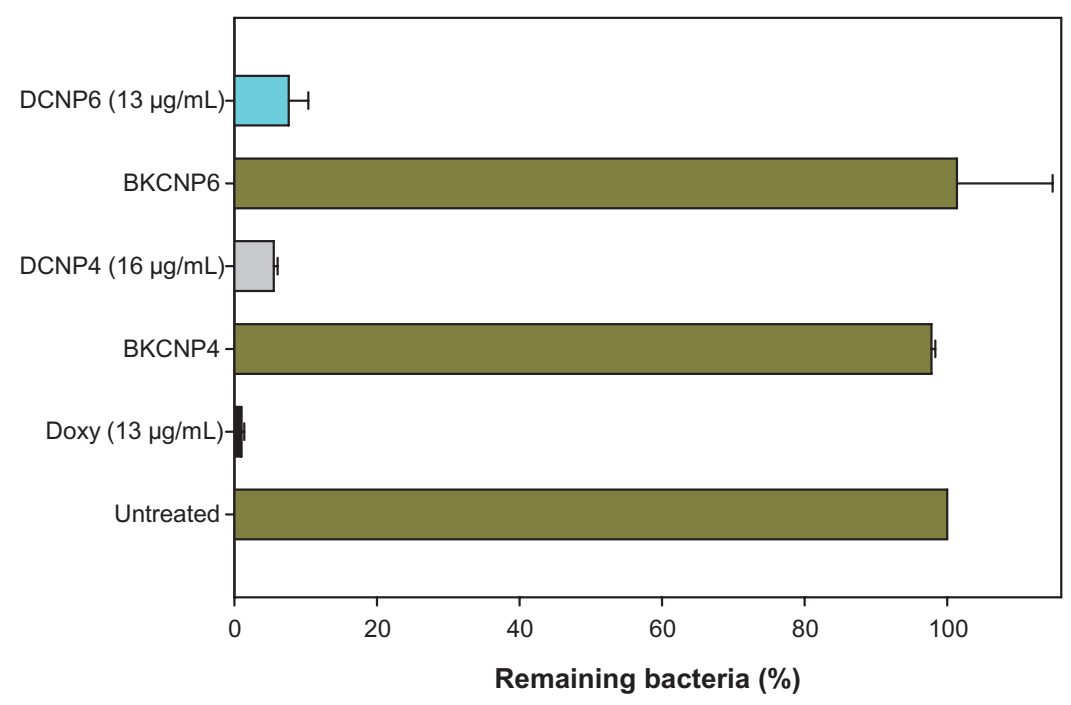

Figure 3 Inhibitory effects of drug-loaded chitosan nanoparticles on bacterial growth, expressed in terms of percentage of remaining bacteria after 4 hours of treatment. Minimum inhibitory concentration values are as follows: DCNP4 $=16 \mu \mathrm{g} / \mathrm{mL}$, DCNP6 $=13 \mu \mathrm{g} / \mathrm{mL}$, and Doxy $=13 \mu \mathrm{g} / \mathrm{mL}$. The untreated tube was used to define the "I00\% remaining" (no inhibition) case.

Note: Data shown are the mean \pm standard deviation $(n=3)$. 

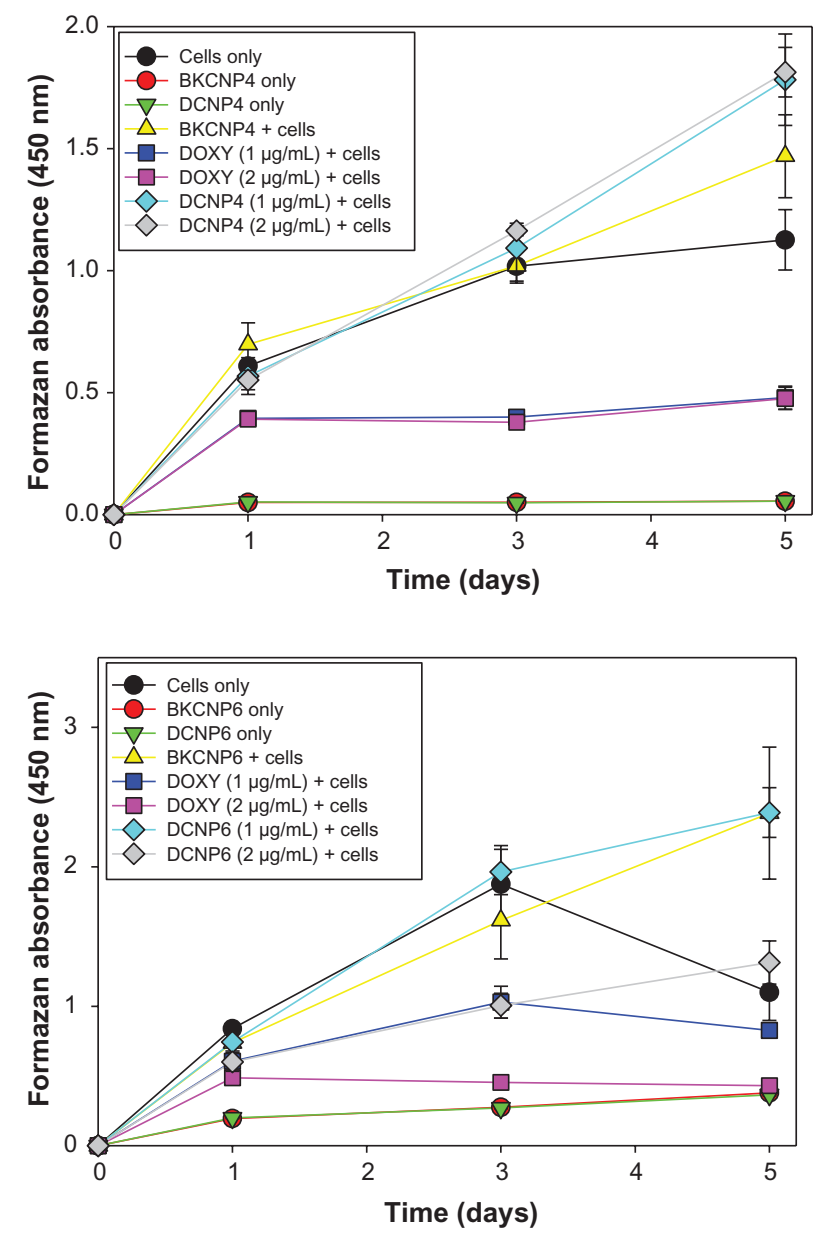

Figure 4 Five-day cell viability for human ovarian surface epithelial cells exposed to blank nanoparticles, drug-loaded nanoparticles, and unencapsulated doxycycline. A higher formazan absorbance indicates greater cell viability. Note: Data shown are the mean \pm standard deviation $(n=3)$.

Doxycycline-induced cytotoxicity was confirmed visually by observations of cell morphology following exposure to doxycycline. Cells treated with $1 \mu \mathrm{g} / \mathrm{mL}$ and $2 \mu \mathrm{g} / \mathrm{mL}$ dosages of doxycycline show the morphology of dead cells. The morphological effects of treating with DCNP4 (at $2 \mu \mathrm{g} / \mathrm{mL}$ ) and unencapsulated doxycycline (also at $2 \mu \mathrm{g} / \mathrm{mL}$ ) are illustrated in Figure 5. Note that the cells treated with the DCNPs were of the same morphology as the untreated cells further demonstrating that encapsulation of doxycycline into chitosan nanoparticles minimizes adverse effects of the drug.

\section{Conclusion}

DCNPs were synthesized and characterized to explore properties that may improve drug delivery and efficacy. Two types of nanoparticles were formulated with differing concentrations of crosslinker: DCNP4 and DCNP6, with the DCNP6 formulation containing approximately 1.5 times
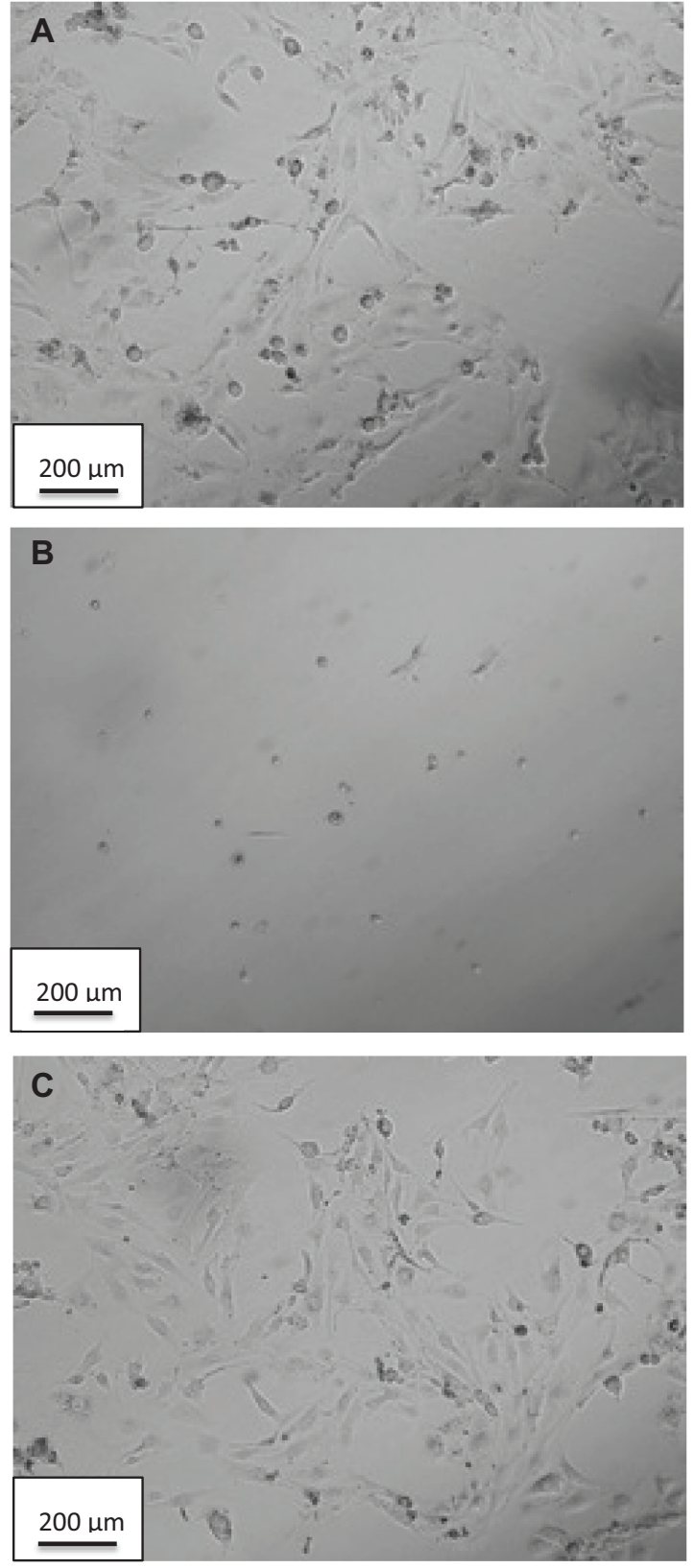

Figure 5 Bright-field images of human ovarian surface epithelial cells after being exposed to (A) no treatment (control), (B) doxycycline at $2 \mu \mathrm{g} / \mathrm{mL}$, and (C) DCNP4 at $2 \mu \mathrm{g} / \mathrm{mL}$.

Note: Magnification I0×.

more TPP crosslinker. Particle diameters ranged from 30 to $220 \mathrm{~nm}$ (DCNP4) and from 200 to $320 \mathrm{~nm}$ (DCNP6); average diameters were $44.50 \mathrm{~nm}$ (DCNP4) and $280 \mathrm{~nm}$ (DCNP6). Both types of drug-loaded chitosan nanoparticles were spherical, with encapsulation efficiencies of approximately $50 \%$. For both formulations, encapsulated doxycycline was released slowly into solution from the particles, with an initial burst effect followed by sustained release over a 24-hour period. Total in vitro release of doxycycline 
over 24 hours was $10 \%$ higher for the larger DCNP6 particles than for DCNP4. Both formulations inhibited the growth of $E$. coli after 4 hours of incubation. MBC values were $<50 \mu \mathrm{g} / \mathrm{mL}$. The DCNPs induced significantly less apparent cytotoxicity than did the unencapsulated doxycycline, which showed significantly high cytotoxicity against normal OSE cells. These results demonstrate that encapsulation of doxycycline into chitosan nanoparticles minimizes adverse side effects of the drug while also effectively releasing the antibiotic in a slow and sustained manner. Therefore, we have demonstrated that DCNPs have the potential of treating E. coli, a common copathogen in PID, in a slow sustained manner while reducing the cellular toxicity to non-bacterial cells that is normal when doxycycline is used in its unencapsulated form. Our future work is to test these DCNPs in an adequate biofilm model that closely mimics the biofilm of the uterus.

\section{Acknowledgments}

This material is based upon work supported by the University South Florida (USF) College of Engineering Interdisciplinary Scholarship Program. We would like to thank the Florida Education Fund McKnight Doctoral Fellowship and the National GEM Consortium PhD Fellowship for their financial support to Natasha Cover. We would also like to thank Dr Don Cameron, Dr Peter Medveckzy, Shara Pantry, and Yvonne Davis from the USF College of Medicine and Regina Easley from the USF College of Marine Science for their help and suggestions.

\section{Disclosure}

The authors report no conflicts of interest in this work.

\section{References}

1. Crossman SH. The challenge of pelvic inflammatory disease. Am Fam Physician. 2006;73(5):859-864.

2. Haggerty CL, Ness R. Newest approaches to treatment of pelvic inflammatory disease: a review of recent randomized clinical trials. Clin Infect Dis. 2007;44(7):953-960.

3. Walker CK, Wiesenfeld HC. Antibiotic therapy for acute pelvic inflammatory disease: the 2006 Centers for Disease Control and Prevention sexually transmitted diseases treatment guidelines. Clin Infect Dis. 2007;44(Suppl 3):S111-S122.

4. Sweet R. Role of bacterial vaginosis in pelvic inflammatory disease. Clin Infect Dis. 1995;20(2):271-275.

5. Peterson HB, Galaid EI, Zenilman JM. Pelvic inflammatory disease: review of treatment options. Rev Infect Dis. 1990;12(6):656-664.

6. Rein DB, Kassler WJ, Irwin KL, Rabiee L. Direct cost of pelvic inflammatory disease and its sequelae: decreasing but still substantial. Obstet Gynecol. 2000;95(3):397-402.

7. Centers for Disease Control and Prevention. Sexually transmitted diseases treatment guidelines. MMWR. 2010;59(RR-12):1-109.

8. Riond J, Riviere J. Pharmacology and toxicology of doxycycline. Vet Hum Toxicol. 1988;30(5):431-443.

9. Joshi N, Miller DQ. Doxycycline revisited. Arch Intern Med. 1997; 157(13):1421-1428.
10. Cunha BA, Domenico P, Cunha CB. Pharmacodymanics of doxycycline. Clin Microbiol Infect. 2001;6(5):270-273.

11. Gencosmanoglu R, Kurtkaya-Yapicier O, Tiftikci A, Avsar E, Tozun N, Oran ES. Mid-esophageal ulceration and candidiasis-associated distal esophagitis as two distinct clinical patterns of tetracycline or doxycycline-induced esophageal injury. J Clin Gastroenterol. 2004;38(6):484-489.

12. Morris TJ, Davis TP. Doxycycline-induced esophageal ulceration in the US Military service. Mil Med. 2000;165(4):316-319.

13. Tahan V, Sayrak H, Bayar N, Erer B, Tahan G, Dane F. Doxycyclineinduced ulceration mimicking esophageal cancer. Cases J. 2008; 1(1): 144 .

14. Heffner JE, Standerfer RJ, Torstveit J, Unruh L. Clinical efficacy of doxycycline for pleurodesis. Chest. 1994;105(6):1743-1747.

15. Mansson T. Treatment of malignant pleural effusion with doxycycline. Scand J Infect Dis Suppl. 1988;53:29-34.

16. Robinson LA, Fleming WH, Galgraith TA. Intrapleural doxycycline control of malignant pleural effusions. Ann Thorac Surg. 1993; 55(5):1115-1121.

17. Hurewitz AN, Lidonicci K, Wu CL, Zucker S. Histologic changes of doxycycline pleurodesis in rabbits. Effect of concentration and $\mathrm{pH}$. Chest. 1994;106(4):1241-1245.

18. Pulsiripunya C, Youngchaiyud P, Pushpakom R, Maranetra N, Nana A, Charoenratanakul $\mathrm{S}$. The efficacy of doxycycline as a pleural sclerosing agent in malignant pleural effusion: a prospective study. Respisology. 1996;1(1):69-72.

19. Venugopal P. Medical pluerodesis. Pulmon. 2007;9(2):51-56.

20. Davies RP, McClymont T, Boshell D. Utlrasound guided chemical pluerodesis with doxycycline. Diagn Ultrasound. 2005;8(3): $23-27$.

21. Zhang H, Wu S, Tao Y, Zang L, Su Z. Preparation and characterization of water-soluble chitosan nanoparticles as protein delivery system. J Nanomater. 2009;2010:1-5.

22. Muhammed R, Junise V, Saraswathi P, Krishnan P, Dilip C. Development and characterization of chitosan nanoparticles loaded with isoniazid for the treatment of tuberculosis. Res J Pharm Biol Chem Sci. 2010;1(4):383-390.

23. Phaechamud T, Charoenteeraboon J. Antibacterial activity and drug release of the chitosan sponge containing hyclate. AAPS Pharm Sci Tech. 2008;9(3):829-835.

24. Ko JA, Park HJ, Hwang SJ, Park JB, Lee JS. Preparation and characterization of chitosan microparticles intended for controlled drug delivery. Int J Pharm. 2002;249(1-2):165-174.

25. Xi-Peng G, Da-Ping Q, Kai-Rong L, Tao W, Peng X, Mai KC. Preparation and characterization of cationic chitosan-modified poly(D,L-lactide-co-glycolide) copolymer nanospheres as DNA carriers. J Biomater Appl. 2008;22(4):353-371.

26. Sarmento B, Ribeiro A, Veiga F, Ferreira D. Development and characterization of new insulin containing polysaccharide nanoparticle. Colloids Surf B Biointerfaces. 2006;53(2):193-202.

27. Goycoolea FM, Lollo G, Remunan-Lopez G, Quaglia F, Alonso MJ. Chitosan-alginate blended nanoparticles as carriers for the transmucosal delivery of macromolecules. Biomacromolecules. 2009;10(7):1736-1743.

28. Tokumitsu H, Ichikawa H, Fukumori Y. Chitosan-gadopentetic acid complex nanoparticles for gadolinium neutron-capture therapy of cancer: preparation by novel emulsion-droplet coalescence technique and characterization. Pharm Res. 1999;16(12):1830-1835.

29. Shanmuganathan S, Shanumugasundaram N, Adhirajan N, RamyaaLakshmi TS, Babu M. Preparation and characterization of chitosan microsphere for doxycycline delivery. Carbohydrate Polymers. 2007; 73(2):201-211.

30. Mohanraj VJ, Chen Y. Nanoparticle: a review. Trop J Pharm Res. 2006; 5(1):561-573.

31. Pinto Reis C, Neufeld RJ, Ribeiro AJ, Veiga F. Nanoencapsulation I. Methods for preparation of drug-loaded polymeric nanoparticles. Nanomedicine. 2006;2(1):8-21. 
32. Wang JJ, Zeng ZW, Xiao RZ, et al. Recent advances of chitosan nanoparticles as drug carriers. Int J Nanomedicine. 2011;6:765-774.

33. Racovita S, Vasiliu S, Popa M, Luca C. Polysaccharides based on microand nanoparticles obtained by ionic gelation and their application as drug delivery systems. Revue Roumaine de Chimie. 2009;54(9):709-718.

34. Tiyaboonchai W. Chitosan nanoparticles: a promising system for drug delivery. Naresuan Uni J. 2003;11(3):51-66.

35. Agnihotri SA, Mallikarjuna NN, Aminabhavi TM. Recent advances on chitosan-based micro- and nanoparticles in drug delivery. J Control Release. 2004;100(1):5-28.

36. Nagpa K, Kumar-Singh S, Nath-Mishr D. Chitosan nanoparticles: a promising system in novel drug delivery. Chem Pharm Bull. 2010;58(11):1423-1430.

37. Grenha A, Seijo B, Serra C, Remunan-Lopez C. Chitosan nanoparticleloaded mannitol microspheres: structure and surface characterization. Biomacromolecules. 2007;8(7):2072-2079.
38. Clavo P, Vila-Jato J, Alonso MJ. Evalution of catonic polymer coated nanocapsules as ocular drug carriers. J Pharma. 1997;153(1):41-50.

39. Mehrotra A, Nagarwal RC, Kumar-Pandit J. Lomustine loaded chitosan nanoparticles: characterization and in-vitro cytotoxicity on human lung cancer cell line L13. Chem Pharm Bull. 2011;59(3):315-320.

40. Alameh M, Jean M, DeJesus D, Buschmann MD, Merzouk A. Chitosanase-based method for RNA isolation from cells transfected with chitosan/siRNA nanocomplexes for real-time RT-PCR in gene silencing. Int J Nanomedicine. 2010;5:473-481.

41. Lee YS, Jang KA, Cha JD. Synergistic antibacterial effect between silibinin and antibiotics in oral bacteria. J Biomed Biotechnol. 2012 article ID 618081 .
International Journal of Nanomedicine

\section{Publish your work in this journal}

The International Journal of Nanomedicine is an international, peerreviewed journal focusing on the application of nanotechnology in diagnostics, therapeutics, and drug delivery systems throughout the biomedical field. This journal is indexed on PubMed Central,

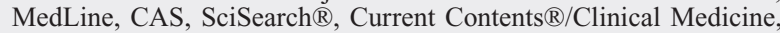

\section{Dovepress}

Journal Citation Reports/Science Edition, EMBase, Scopus and the Elsevier Bibliographic databases. The manuscript management system is completely online and includes a very quick and fair peer-review system, which is all easy to use. Visit http://www.dovepress.com/ testimonials.php to read real quotes from published authors.

Submit your manuscript here: http://www.dovepress.com/international-journal-of-nanomedicine-journal 